ORIGINAL ARTICLE

\title{
ROS-generating NADPH oxidase NOX4 is a critical mediator in oncogenic H-Ras-induced DNA damage and subsequent senescence
}

\author{
U Weyemi ${ }^{1,2,3}$, O Lagente-Chevallier ${ }^{1,2,3}$, M Boufraqech ${ }^{1,2,3}$, F Prenois ${ }^{1,2,3}$, F Courtin ${ }^{1,2,3}$, \\ B Caillou ${ }^{3}$, M Talbot ${ }^{1,3}$, M Dardalhon ${ }^{2,4}$, A Al Ghuzlan ${ }^{1,3}$, J-M Bidart ${ }^{1,2,3}$, \\ M Schlumberger ${ }^{1,2,3}$ and C Dupuy ${ }^{1,2,3}$
}

${ }^{1}$ University Paris-Sud, Orsay, France; ${ }^{2}$ UMR 8200 CNRS, Villejuif, France; ${ }^{3}$ Institut Gustave Roussy, Villejuif, France and ${ }^{4}$ Institut Curie section Recherche, UMR 3348 CNRS, Orsay, France

Activated Ras oncogene induces DNA-damage response by triggering reactive oxygen species (ROS) production and this is critical for oncogene-induced senescence. Until now, little connections between oncogene expression, ROS-generating NADPH oxidases and DNA-damage response have emerged from different studies. Here we report that $H$-RasV12 positively regulates the NADPH oxidase system NOX4-p22 $2^{\text {phox }}$ that produces $\mathrm{H}_{2} \mathrm{O}_{2}$. Knocking down the NADPH oxidase with small interference RNA decreases H-RasV12-induced DNA-damage response detected by $\gamma-\mathrm{H} 2 \mathrm{~A} . \mathrm{X}$ foci analysis. Using HyPer, a specific probe for $\mathrm{H}_{2} \mathrm{O}_{2}$, we detected an increase in $\mathrm{H}_{2} \mathrm{O}_{2}$ in the nucleus correlated with NOX4-p22 ${ }^{\text {phox }}$ perinuclear localization. DNA damage response can be caused not only by H-RasV12-driven accumulation of ROS but also by a replicative stress due to a sustained oncogenic signal. Interestingly, NOX4 downregulation by siRNA abrogated H-RasV12 regulation of CDC6 expression, an essential regulator of DNA replication. Moreover, senescence markers, such as senescence-associated heterochromatin foci, PML bodies, HP1及 foci and p21 expression, induced under $H$-RasV12 activation were decreased with NOX4 inactivation. Taken together, our data indicate that NADPH oxidase NOX4 is a critical mediator in oncogenic H-RasV12-induced DNA-damage response and subsequent senescence.

Oncogene (2012) 31, 1117-1129; doi:10.1038/onc.2011.327; published online 15 August 2011

Keywords: oncogenic H-RasV12; ROS; NADPH oxidase NOX4; DNA damage; senescence

\section{Introduction}

Studies in normal cells have shown that forced expression of oncogenic H-Ras can induce a senescence-like permanent growth arrest (Serrano et al., 1997; Lin et al.,

Correspondence: Dr C Dupuy, Institut Gustave-Roussy, UMR8200 CNRS, 114 rue Edouard Vaillant, Villejuif 94805, France.

E-mail: dupuy@igr.fr

Received 7 September 2010; revised 6 June 2011; accepted 24 June 2011; published online 15 August 2011
1998; Lin and Lowe, 2001). Senescence was initially identified as a response of tissue culture cells to activated oncogene, but its relevance to human cancer has been demonstrated in preneoplasia with expression of DNA damage response markers (Bartkova et al., 2005; Gorgoulis et al., 2005). Indeed, DNA damage signalling contributes to oncogene-induced senescence (Mallette et al., 2007). The fact that senescence is more common in preneoplasia than in neoplasia indicates that senescence might serve as a barrier to oncogenesis (Bartkova et al., 2005).

The mechanism by which deregulated oncogenes induce DNA damage remains unclear, and may arise from distinct mechanisms that vary depending on the specific oncogene, the level of oncogene expression and cellular context. One possibility is that the DNA damage response is triggered by excessive replication caused by a sustained oncogenic signal (Bartkova et al., 2006; Di Micco et al., 2006). In this case, senescent cells present an increased number of active replicons and exhibit defects in DNA replication fork progression (Di Micco et al., 2006). Another possible mechanism involves increased cellular levels of reactive oxygen species (ROS) that will cause DNA damage, such as guanine oxidation, single- and double-strand breaks. This is in accordance with the fact that Ras-expressing cells either cultured in low oxygen condition or treated with a hydrogen peroxide scavenging agent, such as $N$-acetyl cysteine (NAC), blocked Ras-induced senescence (Lee et al., 1999; Vafa et al., 2002). H-Ras can induce ROS production (Leikam et al., 2008). However, the mechanism through which Ras expression triggers a rise in ROS levels within cells, and how ROS function in the case of Ras-induced senescence remain unclear.

For a long time ROS, except those produced by the NADPH oxidase of phagocytes, were considered as metabolic by-products whose degradation is ensured by various antioxidant enzymatic systems. However, they are currently also seen as intra- and extracellular messengers whose production must be sharply controlled. This concept was reinforced since 1999 by the discovery of six new NADPH oxidases whose single function is to produce ROS. They constitute a new family of enzymes known as NOX/DUOX (Bedard and Krause, 2007), found at different cell locations and 

have shown that overexpression of human NOX1 complex in mammalian cells or activation of the catalytic subunit of the leucocyte NADPH oxidase NOX2 by the Epstein-Barr virus nuclear antigen-1 in B cells induced DNA damage and genomic instability (Chiera et al., 2008; Gruhne et al., 2009). Although NADPH oxidases were recently found to induce premature senescent growth arrest in primary endothelial cells (Schilder et al., 2009, Lener et al., 2009), their role in oncogeneinduced senescence has not yet been established.

Oncogenic Ras is believed to have roles in the initiation and progression of thyroid tumors, based on the high frequency of Ras mutations in benign and malignant thyroid tumors (Suarez et al., 1990; Tallini, 2002). To investigate the role of ROS-generating NADPH oxidases in oncogene-induced DNA damage response, we established a conditional expression of H-RasV12 under the control of doxycycline in human non-tumoral thyroid cell line (HThy-ori3.1). Using this system, we found that NOX4 has a critical role in DNAdamage response induced by oncogenic H-Ras.

\section{Results}

\section{Oncogenic $H$-RasV12 positively regulates}

\section{ROS-generating NADPH oxidase}

In a recent study, we highlighted that the NADPH oxidase NOX4 and its functional partner p22 $2^{\text {phox }}$ are expressed inside human thyrocytes (Weyemi et al., 2010). To investigate whether NOX4 is regulated by oncogenic Ras, we transduced human thyrocytes with expression vector carrying cDNA for H-RasV12. As shown in Figure 1a, NOX4 protein level was upregulated in response to $\mathrm{H}-\mathrm{RasV} 12$. To investigate the mechanism of this regulation, we wondered whether $\mathrm{H}$ RasV12 expression is directly involved in the transcriptional regulation of NOX4. The time course of the effect of H-RasV12 on NOX4 mRNA expression was done by real-time (RT)-qPCR. Figure $1 \mathrm{~b}$ shows that overexpression of the activated oncogene induced an increase in NOX4 (2-35-fold) mRNA levels with a greater variation between 24 and $36 \mathrm{~h}$.

We analyzed the expression of the NADPH oxidase in HThy-ori. As shown by RT-PCR analysis (Figure 2a), NOX4 gene is also expressed in HThy-ori cell line where its functional partner $\mathrm{p} 22^{\text {phox }}$ is detected. Transduction of HThy-ori cells with $\mathrm{H}-\mathrm{RasV} 12$ vector preferentially resulted in upregulation of NOX4 mRNA levels when compared with other NOX/DUOX mRNA levels as evaluated by $\mathrm{RT}-\mathrm{qPCR}$. In addition, $\mathrm{p} 22^{\text {phox }}$ protein level was upregulated in this condition as shown by immunofluorescence and western blot analysis (Figure 2b). As expected, Nox4 protein level was also induced in this condition (Figure 2b). These results prompted us to perform a doxycycline-inducible expression system in HThy-ori cells for conditional expression of H-RasV12. Two of clones had a high level of expression after induction and showed a refringent morphology upon doxycycline treatment for $48 \mathrm{~h}$

a
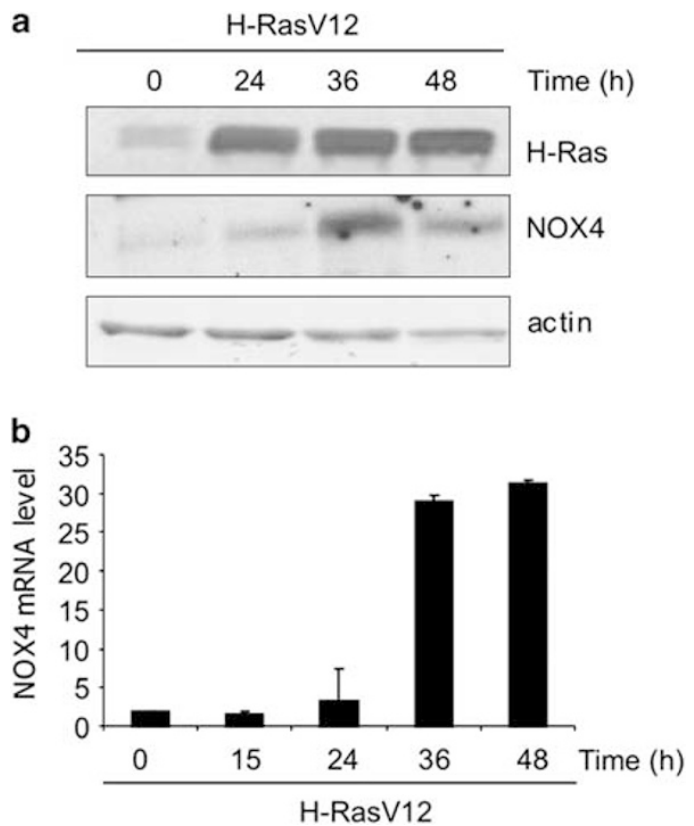

Figure 1 H-RasV12 regulates NOX4 in human thyrocytes. (a) Time-dependant induction of NOX4 by H-Ras in human thyrocytes. Primary human thyrocytes were maintained in $5 \mathrm{H}$ medium and transduced with $\mathrm{H}$-RasV12-expressing vector. NOX4 protein was analyzed in western blot as described in Materials and methods. $\beta$-Actin was used as loading control. (b) NOX4 mRNA was quantified by RT-PCR. Expression values ( $y$-axis) are displayed on base 2 logarithmic scale.

(Supplementary Figure S1). The time course of doxycycline assays showed that H-RasV12 expression upregulated NOX4 and p22 ${ }^{\text {phox }}$ protein levels (Figure 2c). Immunohistochemistry analysis confirmed the induction of NOX4 expression in these conditions (Figure 2d). Doxycycline treatment by itself did not induce NOX4 expression in original HThy-ori cells (Figure 2e).

\section{Activated Ras oncogene promotes $\mathrm{H}_{2} \mathrm{O}_{2}$ generation via NADPH oxidase NOX4}

Induction of H-RasV12 expression by doxycycline in HThy-ori cells was also accompanied by an increase in ROS levels as determined by flow cytometry analysis of DCFHDA oxidation (Figure 3a). Knocking down NOX4 with specific siRNA reduced the levels of ROS in H-RasV12-inducible cells (Figure 3a) indicating that the activated oncogene triggered ROS production via NOX4 regulation. In addition, treatment of cells with NAC, an antioxidant specific for $\mathrm{H}_{2} \mathrm{O}_{2}$, affected ROS levels measured in these conditions. A genetically encoded highly specific fluorescent probe has been recently developed for detecting $\mathrm{H}_{2} \mathrm{O}_{2}$ inside living cells (Belousov et al., 2006). This indicator, named HyPer, has been shown to have submicromolar affinity to $\mathrm{H}_{2} \mathrm{O}_{2}$ and to be insensitive to other oxidants. Using the mammalian expression vectors encoding nuclear-targeted HyPer, we visualized changes in the fluorescence of HyPer in nucleus upon doxycycline treatment for $24 \mathrm{~h}$. This result indicated that $\mathrm{H}-\mathrm{RasV} 12$ regulated the $\mathrm{H}_{2} \mathrm{O}_{2}$ production near or inside the nucleus (Figure $3 \mathrm{~b}$ ). 
a

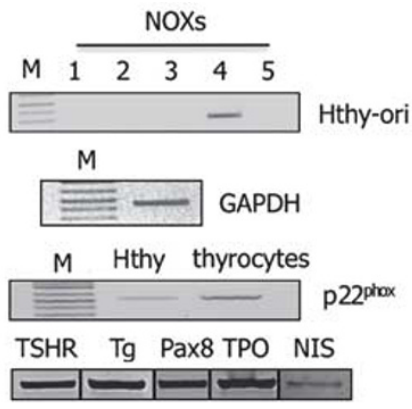

b

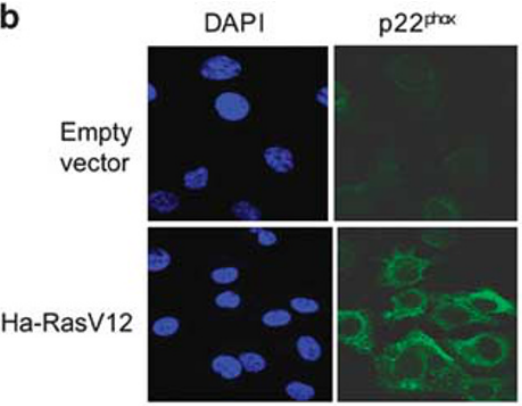

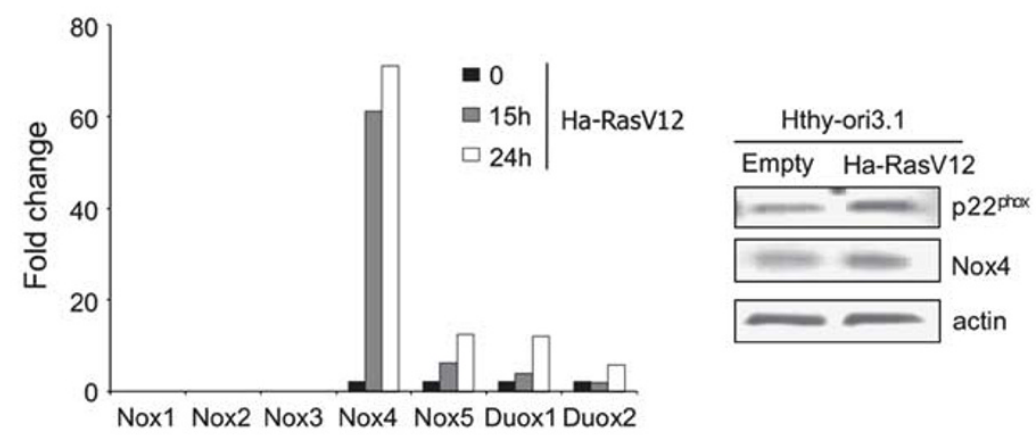

C

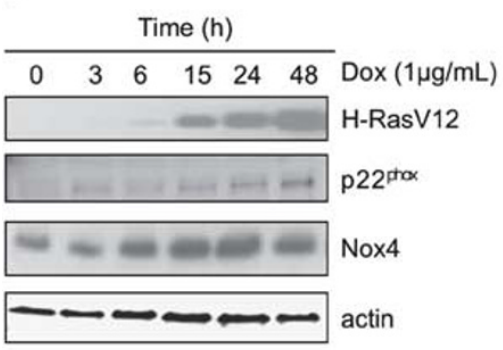

d

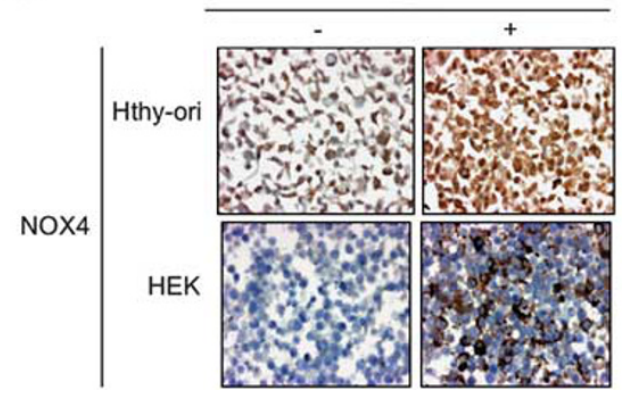

e

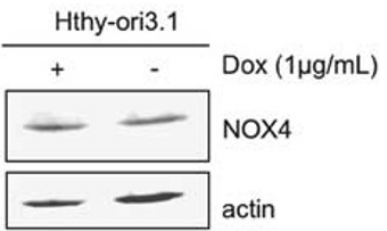

Figure 2 H-RasV12 regulates NOX4-p22 $2^{\text {phox }}$ system in human thyroid cells HThy-ori. (a) Expression of NOXs in HThy-ori3.1 by RT-PCR. Lane M, DNA size markers; lane 1, NOX1; lane 2, NOX2; lane 3, NOX3; lane 4, NOX4 and lane 5, NOX5. Expression of p22 $2^{\text {phox }}$ was also analyzed by RT-PCR. Human thyrocytes were used as positive control with mRNA expression of markers of thyroid differentiation as TSH receptor (TSHR), thyroglobuline (Tg), transcription factor PAX8, thyroperoxidase (TPO) and symporter $\mathrm{Na}^{+} /$ $\mathrm{I}^{-}$(NIS). Expression of G3PDH is reported as internal control. Comparative expression of NOX homologues genes in HThy-ori cells transduced with H-RasV12, analyzed by real-time quantitative reverse transcription-PCR. (b) Immunofluorescence staining of p22 in Hthy-ori3.1 cells transduced for $48 \mathrm{~h}$ with H-RasV12 or empty vector. Nuclei were stained with DAPI (4',6-diamidino-2phenylindole). Magnification $\times 63$. Western blot analysis of NOX4 and p22 phox in HThy-ori cells transduced for $48 \mathrm{~h}$ with $\mathrm{H}-\mathrm{RasV} 12$. (c) Time-dependent induction of NOX4 and p22 $2^{\text {phox }}$ upon H-RasV12-inducible expression with doxycycline $(1 \mu \mathrm{g} / \mathrm{ml})$. $\beta$-Actin was used as loading control. (d) Immunohistochemical analysis of formalin-fixed paraffin-embedded HRasV12-inducible HThy-ori and NOX4inducible HEK293 cells treated for $48 \mathrm{~h}$ with doxycycline $(1 \mu \mathrm{g} / \mathrm{ml})$. (e) Western blot analysis of NOX4 in original HThy-ori cells treated or not with doxycycline $(1 \mu \mathrm{g} / \mathrm{ml})$ for $48 \mathrm{~h}$.

Nuclear expression of Hyper was confirmed by immunofluorescence using anti-green fluorescent protein that specifically recognized this protein as shown by immunoblot analysis (Figure $3 b$ ). In line with this site of $\mathrm{H}_{2} \mathrm{O}_{2}$ production, we used confocal immunofluorescence to determine the respective locations of NOX4 and p $22^{\text {phox }}$ (Figure $3 \mathrm{c}$ ). A weak co-staining with lamin $\mathrm{A} / \mathrm{C}$, a nuclear membrane marker, was found in the nucleus of H-RasV12-inducible cells, and a strong costaining with calreticulin revealed endoplasmic reticulum localization. NOX4 was detected in comparable locations (Figure 3c). Nuclei isolation experiments provided support for nuclear localization for NOX4. Of interest, as shown previously (Hilenski et al, 2004), two NOX4 isoforms were thus detected; the $65 \mathrm{kDa}$ form exclusively found in the nuclear fraction and the $75 \mathrm{kDa}$ form found in the detergent-insoluble nonnuclear fraction containing the endoplasmic reticulum (Figure 3d) Overall, these data indicated that NOX4 and p22 $2^{\text {phox }}$, found to be expressed in nuclear and in perinuclear compartment of $\mathrm{H}$-RasV12-expressing cells, form a functional complex that generates $\mathrm{H}_{2} \mathrm{O}_{2}$ in the nucleus environment.

\section{H-RasV12 activation is sufficient for DNA damage induction}

ROS induce DNA damage in different systems (Chiera et al., 2008; Leikam et al., 2008). Oncogenic Ras triggers 

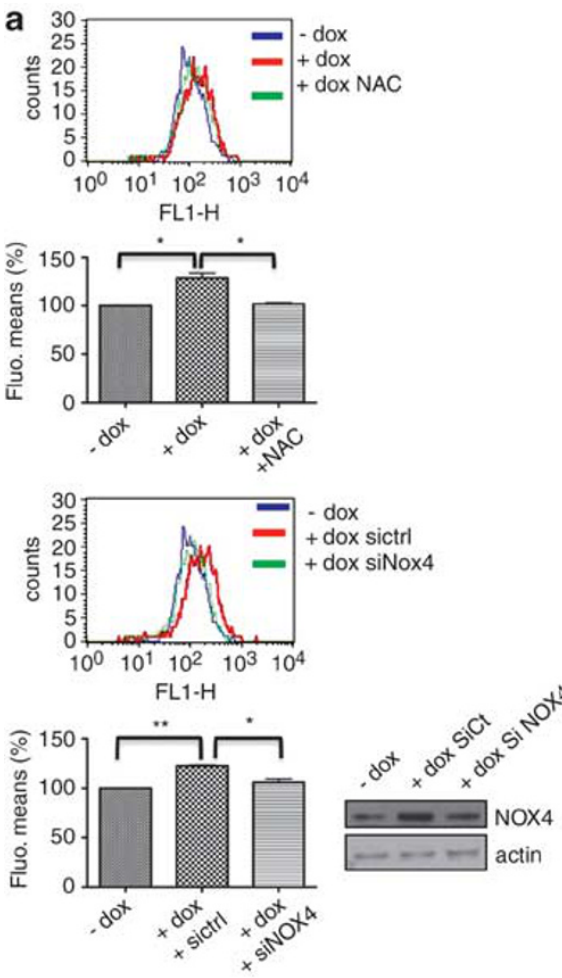

C

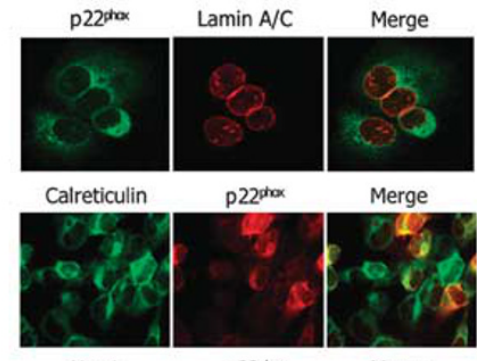

Nox4
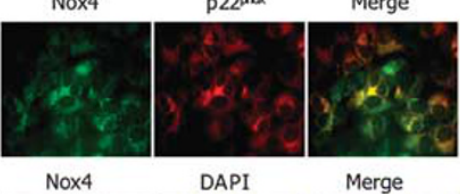

DAPI Merge

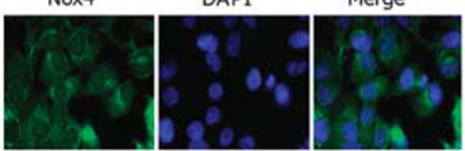

b
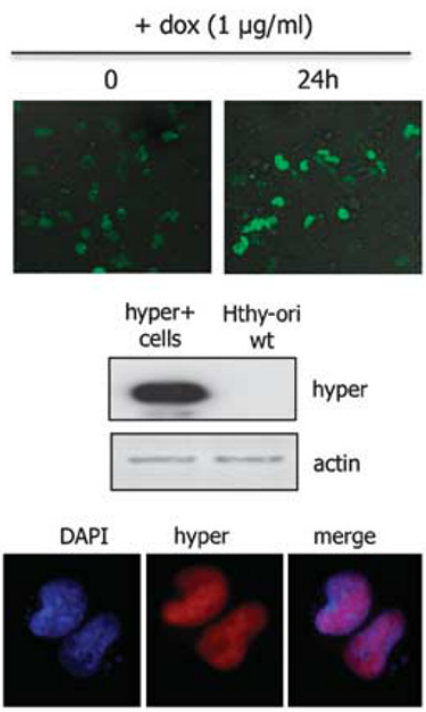

d
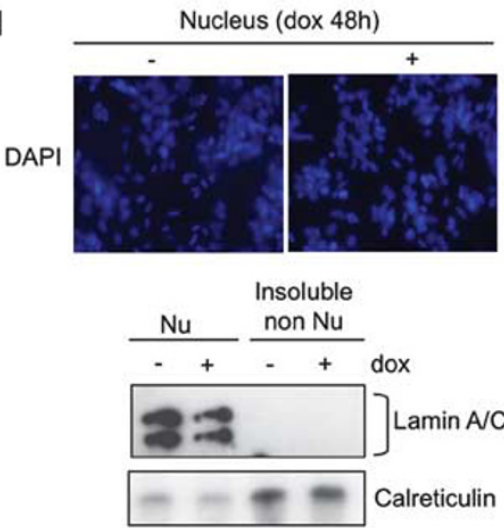

Insoluble

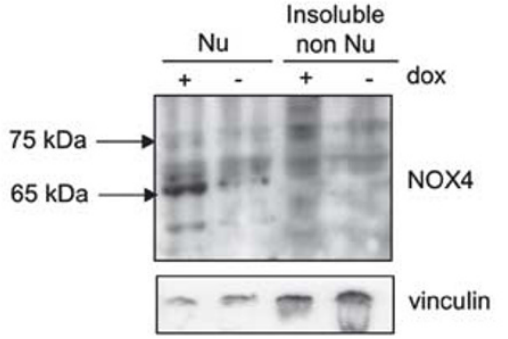

Figure 3 H-RasV12 increases levels of intracellular ROS via NOX4 activity. (a) The intracellular level of ROS was measured in Tet-onregulated H-RasV12 HThy-ori cells by DCF fluorescence using flow cytometry. Before treatment with doxycycline $(1 \mu \mathrm{g} / \mathrm{ml})$ for $48 \mathrm{~h}$, cells were transduced with short interfering RNAs to NOX4 or treated for $30 \mathrm{~min}$ with $5 \mathrm{~mm}$ NAC. Graphs show the quantification of fluorescence mean. Immunoblot detection of NOX4 in HThy-ori cells transduced with siRNA control and siRNA NOX4 SMARTpool, as control. Values are the means \pm s.e. from independent experiments, ${ }^{*} P<0.05$, ${ }^{*} P<0.01$. (b) HyPer response to H-RasV12 induction. Confocal analysis of $\mathrm{H}_{2} \mathrm{O}_{2}$-dependent fluorescence in Tet-on-regulated H-RasV12 HThy-ori cells-expressing pHyPer-nuc. Magnification $\times 20$. Western blot and immunofluorescence analysis of Hyper-nuc transduced in H-RasV12-inducible cells using anti-green fluorescent protein. Magnification $\times 63$. (c) Colocalization between nucleus membrane protein $(\operatorname{laminA} / \mathrm{C})$, endoplasmic reticulum marker (calreticulin), NOX4 and $\mathrm{p} 22^{\text {phox }}$ by immunofluorescence in cells transduced with H-RasV12-expressing vector. Magnification $\times 63$. The nuclei were stained with DAPI (4',6-diamidino-2-phenylindole; blue). (d) Immunoblot detection of NOX4 protein in nuclear fraction $(500 \mathrm{~g}$ pellet, $\mathrm{Nu})$ and insoluble non-nuclear fraction $(200000 \mathrm{~g}$ pellet, non-Nu) of Tet-on-regulated H-RasV 12 HThy-ori cells treated with or without doxycycline $(1 \mu \mathrm{g} / \mathrm{ml})$ for $48 \mathrm{~h}$. Nucleus were stained with DAPI and visualized on microscopy. Magnification $\times 20$. The distribution of NOX4 in non-nuclear and nuclear fractions was characterized using antibodies against fraction-specific proteins: lamin $\mathrm{A} / \mathrm{C}$ for nuclear fraction and calreticulin for reticulum-enriched insoluble non-nuclear fraction.

DNA damage-response signal activation (Bartkova et al., 2006; Di Micco et al., 2006) and $\mathrm{H}_{2} \mathrm{O}_{2}$ is an important mediator in Ras-induced DNA damage
(Mallette et al., 2007). The phosphorylated form of histone $(\gamma-\mathrm{H} 2 \mathrm{AX})$ at serine 139 is generally used as a marker of DNA double-strand breaks (Gorgoulis et al., 
2005, Nuciforo et al., 2007). The HThy-ori cells expressing $\mathrm{H}-\mathrm{RasV} 12$ in a conditional manner were treated with increasing concentrations of doxycycline. Immunoblotting analysis showed that doxycycline at a concentration of $0.5 \mu \mathrm{g} / \mu \mathrm{l}$ was able to promote $\mathrm{H}$ RasV12 expression, which induced phosphorylation of H2AX (Figure 4a). In addition, we performed pulsefield gel electrophoresis assay to analyze DNA fragmentation in our model and detect DNA double-strand breaks. The time course of $\mathrm{H}$-RasV12 expression in response to $1 \mu \mathrm{g} / \mu \mathrm{l}$ of doxycycline was accompanied by an increase in double-strand breaks and was correlated to the increase of the phosphorylated form of histone $(\gamma-\mathrm{H} 2 \mathrm{AX})$ detected in the same conditions by western blot analysis (Figure 4b). Immunofluorescence microscopy of HThy-ori cells transduced with H-RasV12 showed that $\gamma-\mathrm{H} 2 \mathrm{AX}$ foci-positive cells were also highly positive for $\mathrm{p} 22^{\text {phox }}$ (Figure 4c). Large fragments of DNA visualized in pulse-field gel electrophoresis were not usually associated with apoptosis. This result was strengthened by the absence of cell surface

a

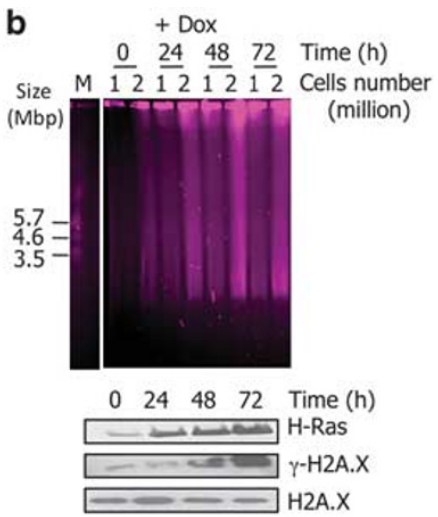

C

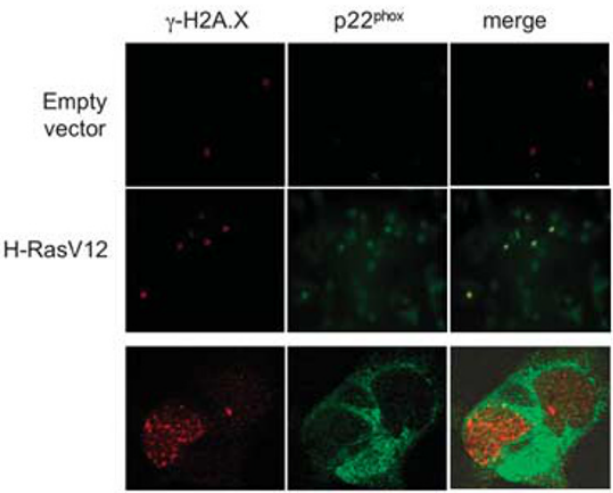

Figure 4 Correlation between H-Ras expression level and DNA damage. (a) Dose-dependent stimulation of $\gamma-\mathrm{H} 2 \mathrm{~A} . \mathrm{X}$ in Teton-regulated H-RasV12 HThy-ori cells treated with doxycycline for $48 \mathrm{~h}$. (b) Increase in DNA fragmentation level upon H-RasV12 activation. Kinetics of double-strand breaks increase measured by pulse field gel electrophoresis in cells after doxycycline treatment $(1 \mu \mathrm{g} / \mathrm{ml})$. Schizosaccharomyces pombe chromosomes are used as DNA size markers. DNA fragmentation is analyzed on 1 million and 2 millions cells as indicated. Time-dependent stimulation of $\gamma$-H2A.X in Tet-on-regulated H-RasV12 HThy-ori cells treated with doxycycline $(1 \mu \mathrm{g} / \mathrm{ml})$ for indicated times. (c) Immunofluorescence of $\gamma-\mathrm{H} 2 \mathrm{AX}$ and $\mathrm{p} 22^{\text {phox }}$ after expression of H-RasV12. Magnification $\times 10$ (middle panel) and $\times 100$ (lower panel). expression of Annexin V, a marker of early-stage apoptosis (Figures 5a and $\mathrm{b}$ ).

\section{ROS-generating NADPH oxidase NOX4 inactivation}

abrogates $H$-RasV12-induced DNA-damage response and subsequent senescence

To determine the role of NOX4 in DNA-damage response induced by $\mathrm{H}$-RasV12, we performed interference RNA experiments. H-RasV12-inducible cells were treated for $48 \mathrm{~h}$ with doxycycline in the presence of NOX4 specific or p22 $2^{\text {phox }}$-specific siRNA and control siRNA. A significant reduction $(40 \%)$ in DNA lesions detected by H2A.X phosphorylation was observed after

a

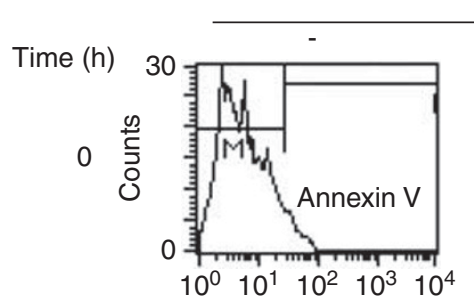

dox
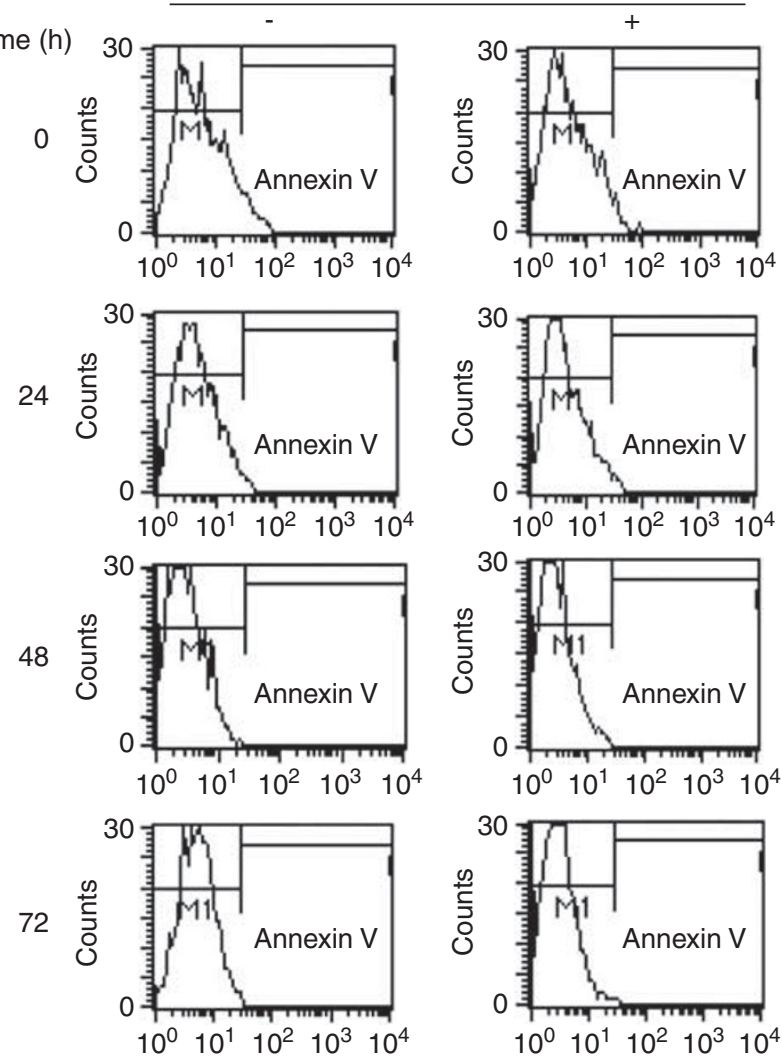

b

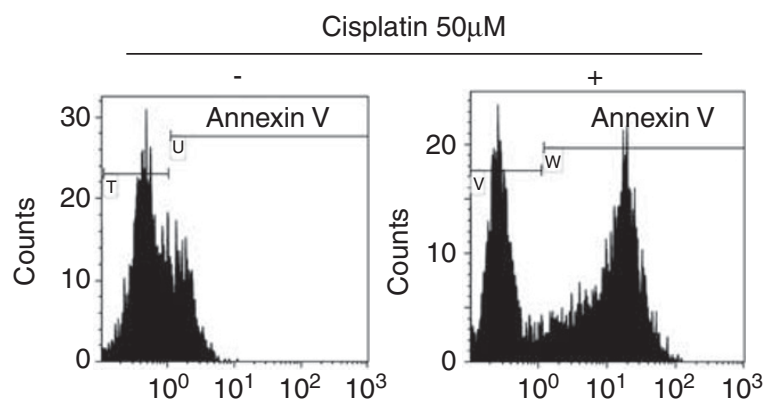

Figure 5 H-Ras expression does not induce apoptosis in HThy-ori cells. (a) Analysis of Annexin V staining upon H-RasV12-inducible expression with doxycycline $(1 \mu \mathrm{g} / \mathrm{ml})$. Cells were harvested on the days indicated and analyzed for cell surface expression of annexin V. (b) Hthy-ori cells treated with cisplatin $(50 \mu \mathrm{M})$ were used as positive control. 
$\mathrm{p} 22^{\text {phox }}$ and NOX4 inactivation (Figure 6a). The same results were obtained by immunofluorescence analysis where NOX4-inactivated cells displayed 50\% reduction of DNA-damage foci (Figures $6 \mathrm{~b}$ and c). In addition, NAC treatment of cells also significantly decreased the DNA-damage foci indicating involvement of $\mathrm{H}_{2} \mathrm{O}_{2}$ in DNA lesions produced under H-RasV12 expression. Taken together these data showed that NOX4- dependent $\mathrm{H}_{2} \mathrm{O}_{2}$ generation participated in $\mathrm{H}-\mathrm{RasV} 12$ induced DNA-damage response.

As several studies suggested that DNA damage response could also be triggered by excessive replication caused by a sustained oncogenic signal (Bartkova et al., 2006; Di Micco et al., 2006), we evaluated the role of NOX4 in DNA replication rate induced by H-RasV12 by analysing the expression of CDC6, an essential a

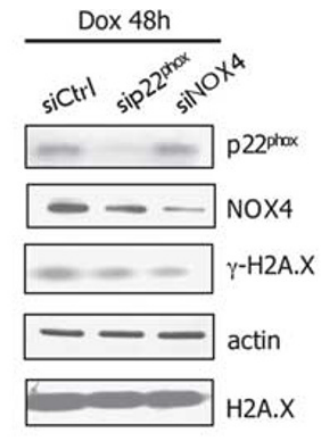

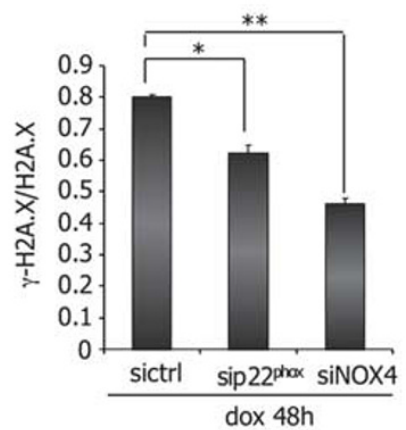

b

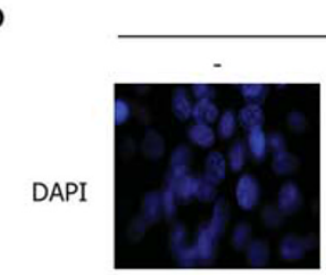

Dox $48 \mathrm{~h}$
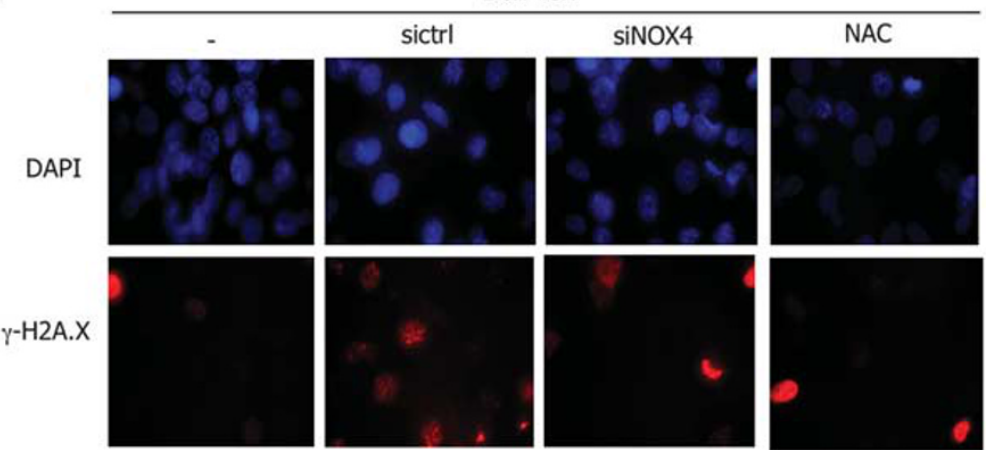

C
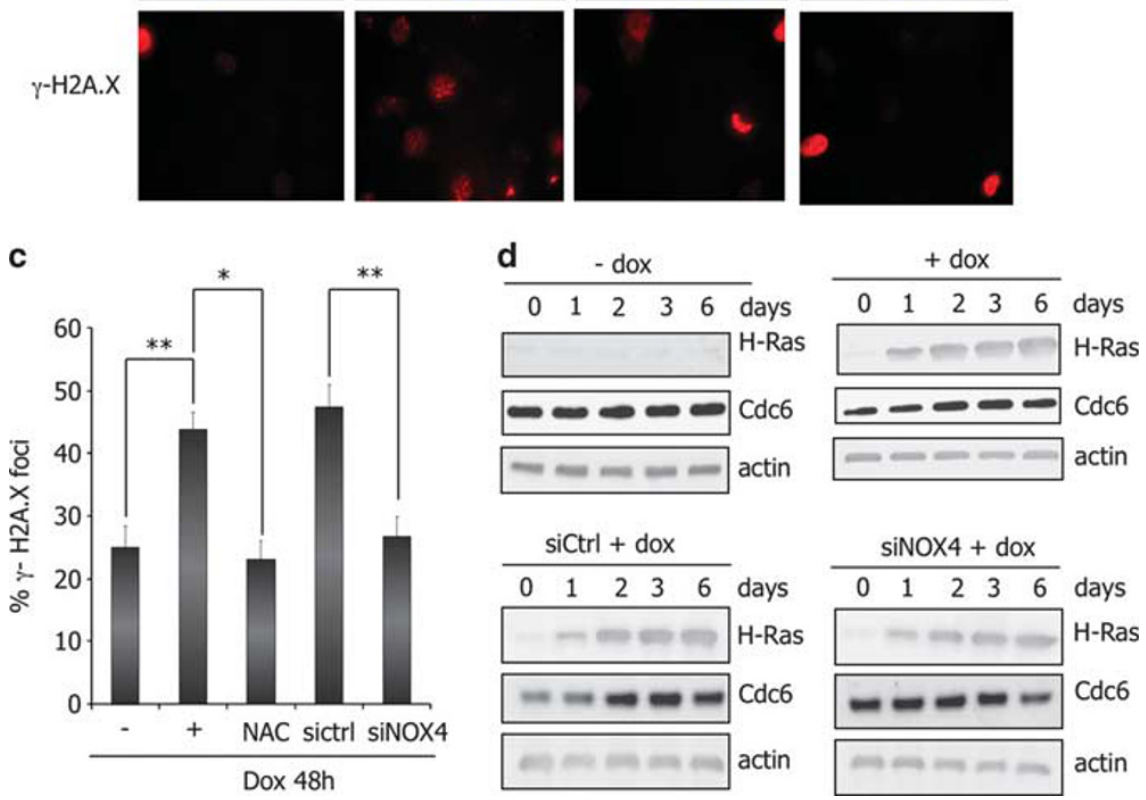

Figure 6 Inhibition of the NADPH oxidase NOX4 abrogates H-Ras-induced DNA-damage response. (a) NOX4 and p2 $2^{\text {phox }}$ knockdown with interference RNA decrease the level of H2A.X phosphorylation in Tet-on-regulated H-RasV12 HThy-ori cells treated with doxycycline $(1 \mu \mathrm{g} / \mathrm{ml})$ for $48 \mathrm{~h}$. Left panel: immunoblots for $\gamma$-H2A.X, p2 $2^{\text {phox }}$ and NOX4. $\beta$-Actin and total H2A.X were used as loading control. Right panel: quantification of $\gamma$-H2A.X intensity by densitometry; ${ }^{*} P<0.05, * * P<0.01$ using the Student's $t$-test. (b) Representative micrographs illustrating $\gamma$-H2A.X staining in cells transduced with interference RNA against NOX4 or pretreated with NAC (5 mM) for $30 \mathrm{~min}$ before addition of doxycycline $(1 \mu \mathrm{g} / \mathrm{ml})$ for $48 \mathrm{~h}$. The nuclei were stained with DAPI (4',6-diamidino2-phenylindole; blue). Magnification $\times 63$. (c) Quantification of the number of $\gamma-\mathrm{H} 2 \mathrm{~A}$.X foci. Histogram indicates the number of cells containing $\gamma$-H2A.X foci among all cells stained with DAPI. The data represent the average and s.d. of three independent counts. (d) Inhibition of NOX4 abrogates H-RasV12-induced CDC6 regulation. H-Ras and CDC6 were visualized by western blot in H-RasV12-inducible cells treated with doxycycline $(1 \mu \mathrm{g} / \mathrm{ml})$ for indicated times. $\beta$-Actin was used as loading control. All experiments were realized with siRNA pool from Dharmacon (Table 1). 
regulator of DNA replication. We observed that $\mathrm{H}$ RasV12-inducible cells treated with doxycycline displayed a transient increase in CDC6 expression as compared with non-treated cells (Figure 6d), NOX4 downregulation by RNA interference was able to counteract H-RasV12-induced CDC6 upregulation, suggesting that NOX4 might dampen DNA replication rate.

It has been demonstrated that DNA-damage response pathways have a major function in mediating senescence (Bartkova et al., 2006; Mallette et al., 2007; Nuciforo et al., 2007). As Ras-induced ROS production was shown to be causative for senescence (Lee et al., 1999) and in line with previous observations, we investigated the involvement of NADPH oxidase NOX4 in Rasinduced senescence. To characterize senescence signals, we performed senescence-associated heterochromatin foci (SAHF) assay as reported previously (Zhang et al., 2005). Figure 7a shows that H-RasV12-inducible cells treated with doxycycline for 6 days displayed an increase in SAHF formation ( $0-25 \%$ cells) as compared with non-treated cells $\left(0-3 \%\right.$ cells). p22 $2^{\text {phox }}$ and NOX4 downregulation by RNA interference resulted in $\sim 60 \%$ and $50 \%$ reduction of cells displaying $\mathrm{SAHF}$, respec-

a
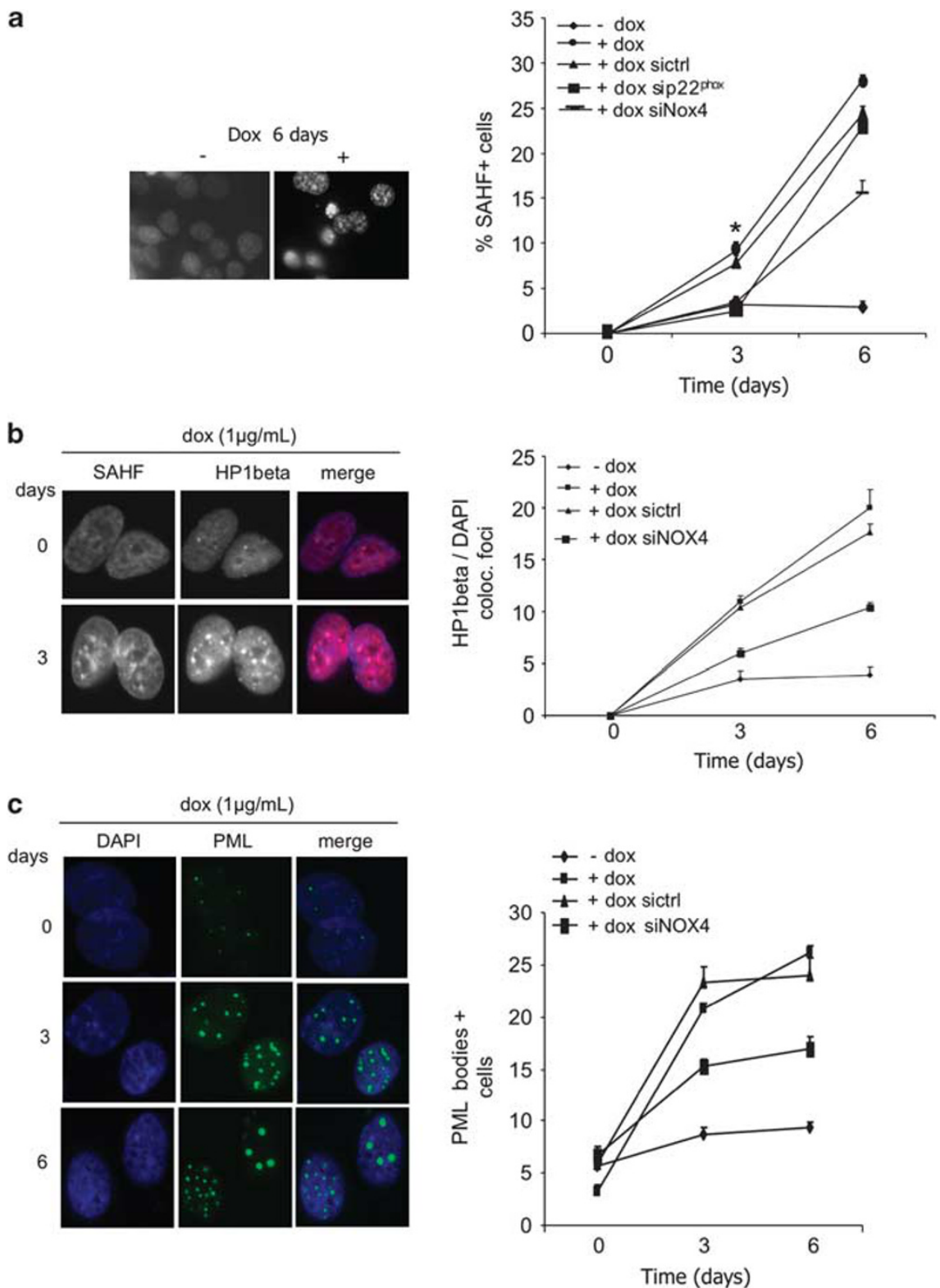

Figure 7 NADPH oxidase NOX4 is involved in H-RasV12-induced senescence. (a) Decrease in SAHF formation after NOX4 inactivation. Tet-on-regulated H-RasV12 HThy-ori cells were transduced with interference RNA against p22 $2^{\text {phox }}$ or NOX4 and treated or not with doxycycline $(1 \mu \mathrm{g} / \mathrm{ml})$ for indicated times, fixed and stained with DAPI (4',6-diamidino-2-phenylindole). Magnification $\times 63$. Results were quantified by scoring 100 cells on three independent slides for each assay from two independent experiments. J3: sictrl vs sip22 $2^{\text {phox }} P=0.039$, sictrl vs siNOX4 $P=0.048$; J6: sictrl vs sip22 ${ }^{\text {phox }} P=0.349$; sictrl vs siNOX4 $P=0.078$ using Student's $t$-test. ${ }^{*} P<0.05$. Colocalizing HP1 $\beta /$ DAPI foci (b) and PML bodies (c) were quantified by scoring 100 cells from each slide. All experiments were realized with siRNA NOX4 pool from Dharmacon (Table 1). 
tively. HP1 $\beta$ and PML bodies largely described as senescence markers were also analyzed. As described previously (Zhang et al, 2005), HP1 $\beta$ colocalized with SAHF in heterochromatin regions (Figure $7 b$ ) and PML bodies become larger and more numerous as cells enter senescence (Figure 7c). Once more, NOX4 inactivation partly counteracts these effects, establishing a link between $\mathrm{H}$-RasV12 activation, $\mathrm{H}_{2} \mathrm{O}_{2}$-generating NADPH oxidase NOX4 activation and senescence.

As cyclin-dependent kinase inhibitors p2 $1^{\mathrm{WAF}}$ (p21) and $\mathrm{p} 16^{\mathrm{INK} 4 \mathrm{~A}}$ (Ink4a) are described to be crucial mediators of senescence in response to oncogenic stress (Collado and Serrano, 2006), we examined their expression upon H-RasV12 activation. The time course of $\mathrm{H}$ RasV12 expression ranging from 0 to $72 \mathrm{~h}$ was accompanied by p21 activation (Figure 8a). On the other hand, p16 ${ }^{\mathrm{INK} 4 \mathrm{~A}}$ expression level did not show any obvious difference indicating that it was not involved in H-RasV12-induced senescence in our system. The NADPH oxidase NOX4 inactivation was able to at least partly counteract H-RasV12-induced p21 expression (Figure $8 \mathrm{~b}$ ) but failed to inhibit p16 $6^{\mathrm{NK} 4 \mathrm{~A}}$. HRasV12-induced senescence resulted in permanent growth arrest as shown in Figure 8c. NOX4 downregulation by RNA interference inhibited the growth arrest induced by oncogenic Ras.

\section{Discussion}

Although previous studies emphasized the role of ROS in oncogene-induced DNA-damage response and senescence (Lee et al., 1999; Mallette et al., 2007), there is little demonstrated links between oncogenic activity, ROS-generating systems and DNA-damage response. In this study, we have demonstrated that oncogenic H-Ras upregulates the NADPH oxidase NOX4 and its functional partner $\mathrm{p} 22^{\text {phox }}$, which produce ROS and thereby induce DNA damage and subsequently senescence.

Several reports have shown that oncogene overexpression is accompanied by the presence of DNA damage foci (Abulaiti et al., 2006; Mallette et al., 2007). The lesions can be readily visualized using antibodies against the phosphorylated form of the histone H2AX (d'Adda di Fagagna et al., 2003). Using the HThy-ori3.1 cells expressing H-RasV12 in a conditional manner we observed that H-RasV12 induced DNA damage as shown by the presence of a nuclear focal pattern of phosphorylated H2AX and promoted senescence by affecting chromatin structure with the formation of SAHFs. This effect was dependent on signal intensity. By using a transgenic mouse model designed to express a doxycycline-regulated mutant H-Ras allele, Sarkisian et al. (2007) showed that the levels of Ras expression correlated with the strength of the senescence response (Sarkisian et al., 2007). Thus, high but not low levels of activated H-Ras are able to trigger senescence in mammary epithelial cells in vivo suggesting that a second "hit" that causes increased levels of the mutant Ras is required to trigger the senescence barrier. Amplification of Ras signaling has been reported a

b
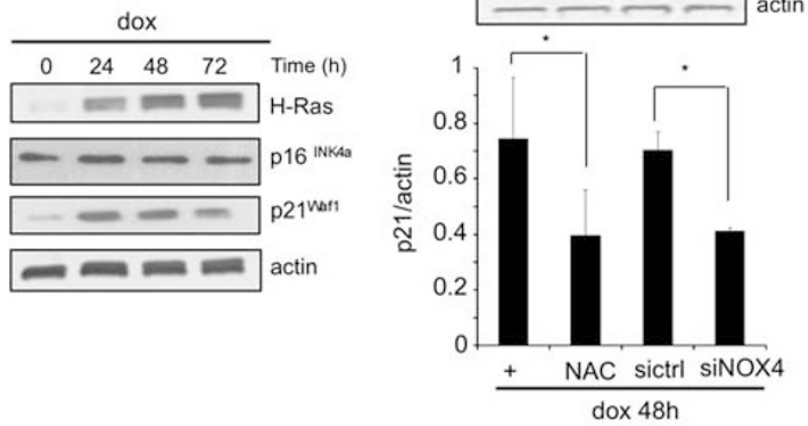

c
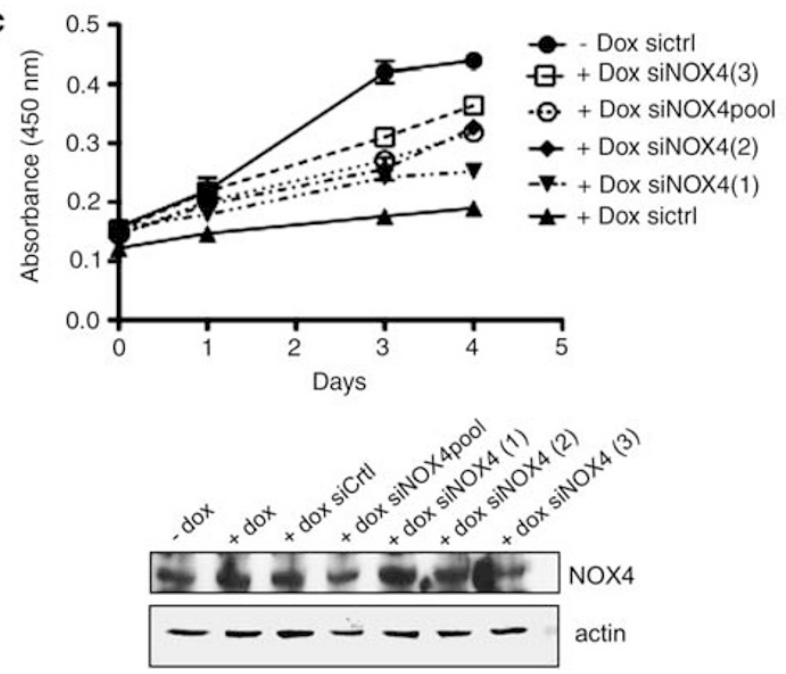

Figure 8 NADPH oxidase NOX4 mediates H-RasV12-induced cell proliferation arrest. (a) Induction of p21 by H-RasV12 in thyroid cells. H-Ras, p16 and p21 were visualized by western blot in Tet-on-regulated H-RasV12 HThy-ori cells treated with doxycycline $(1 \mu \mathrm{g} / \mathrm{ml})$ for indicated times. $\beta$-Actin was used as loading control. (b) NOX4 inactivation abrogates H-Ras-induced p21 expression. Upper panel: immunoblots for p21 in Tet-on-regulated H-RasV12 HThy-ori cells transduced with interference RNA against NOX4 or pretreated with NAC $(5 \mathrm{~mm}, 30 \mathrm{~min})$ before addition of doxycycline. Lower panel: quantification of $\mathrm{p} 21$ intensity by densitometry; ${ }^{*} P<0,05$ using Student's $t$-test. (c) Cell proliferation was evaluated by WST-1 assay as described in Materials and methods. Immunoblot for NOX4 in these cells transduced with different interference RNAs against NOX4. According to cell proliferation experimental data, NOX4-3 siRNA caused a more significant reduction in NOX4 protein. These experiments were realized with siRNA NOX4 pool and the three stealth RNAi duplexes listed in Table 1. $\beta$-Actin was used as loading control.

previously in a different setting (Quintanilla et al., 1986) and also occurs when activated Ras is expressed from its endogenous locus (Guerra et al., 2007).

Several mechanisms have been proposed to mediate DNA damage response under oncogenic stimulation: DNA damage response could be triggered by a replicative stress caused by a sustained oncogenic signal and/or could be caused by an oncogene-driven accumulation of ROS. Oncogene-induced senescence has been proposed to be triggered by accumulation of 
ROS (Lee et al., 1999). Consistent with this hypothesis, oncogene-induced senescence can be bypassed in murine cells by growing cells in low oxygen (MacLaren et al., 2004). Conversely, $\mathrm{H}_{2} \mathrm{O}_{2}$ is also a well-known senescence trigger (Mallette et al., 2007). Notably, ROS scavengers can suppress senescence in some systems (Lee et al., 1999). In agreement with this, we measured by DCF fluorescence a ROS production induced by H-RasV12 expression in human thyroid cells, which caused DNA lesions as revealed by quantification of nuclear $\mathrm{H} 2 \mathrm{AX}$ foci. Treatment of cells with a ROS inhibitor, such as NAC, significantly inhibited DNA damage. Consequently, these cells appeared to be a good experimental model to characterize the mechanism by which $\mathrm{H}$ RasV12 induces ROS production.

NADPH oxidases are good candidates for ROSgenerating systems involved in senescence because NIH3T3 fibroblasts overexpressing transfected NOX4 were found to develop signs of cellular senescence (Geiszt et al., 2000). In a recent study, we have demonstrated the presence of NOX4 and its partner p22 $2^{\text {phox }}$ in human thyrocytes (Weyemi et al., 2010), which are both positively regulated by the thyroid-stimulating hormone. This NADPH oxidase was also found in this study to be the only one expressed and induced by HRasV12 in the HThy-ori3.1. To date, six homologs of the phagocyte NADPH oxidase NOX2 (also known as gp91phox) that generates $\mathrm{O}_{2}^{-}$and $\mathrm{H}_{2} \mathrm{O}_{2}$ have been identified in many tissues. It appears that these enzymes serve as a major source of intracellular ROS that has an important signaling roles (Bedard and Krause, 2007). The complexity of these isoforms in controlling ROS production is increasingly apparent because each isoform has a unique expression pattern, subcellular localization and subunits requirement. The NADPH oxidase NOX4 has been originally identified in the kidney and was shown to produce $\mathrm{H}_{2} \mathrm{O}_{2}$ continuously (Geiszt et al., 2000). Association of NOX4 with $\mathrm{p} 22^{\text {phox }}$ seems to be a prerequisite for localization of the complex to perinuclear vesicles (Serrander et al., 2007). In this study, using immunofluorescence, we found NOX4p $22^{\text {phox }}$ complex localization in the endoplasmic reticulum, but also in the nuclear membrane, in accordance with previous studies (Hilenski et al., 2004; Kuroda et al., 2005; Anilkumar et al., 2008). This perinuclear localization suggested a potential role of NOX4 as a DNA damage agent.

A direct link between the NADPH oxidase and DNA damage was supported by the observation that siRNAmediated abrogation of NOX4 expression or its functional partner $\mathrm{p} 22^{\text {phox }}$ resulted in a significant decrease in DNA damage induced by H-RasV12 expression. Beside producing oxidative DNA damage, it appears that NOX4 might also produce DNA damage by increasing the replication rate. CDC6 that has a key role in regulating the initiation of DNA replication was found in our study to be regulated by NOX4. As observed previously, H-RasV12 led to a transient upregulation of CDC6 (Di Micco et al., 2006), which was abrogated by NOX4 inactivation. The weak expression of CDC6 observed for first $24 \mathrm{~h}$ could result from its degradation that has been described in early phase of replication (Petersen et al., 2000). NOX4 inactivation might prevent this process. Interestingly, in a recent study, a novel regulator of NOX4, Poldip2 has been identified (Lyle et al., 2009). This protein was originally identified as a proliferating cell nuclear antigen and DNA polymerase $\delta$-interacting protein, suggesting a possible function in the nucleus in relation to DNA (Liu et al., 2003).

It has been suggested that DNA damage may precede and trigger SAHF formation (Hemann and Narita, 2007). Interestingly, in this study we show that suppression of the NADPH oxidase NOX4-p22 $2^{\text {phox }}$ expression impaired both DNA damage and SAHF formation. The intensity of SAHF formation was shown to be different depending on the senescence stimulus and the cell type (Hemann and Narita, 2007). Although SAHFs are induced by a variety of stimuli, oncogenic Ras was shown to induce SAHFs most prominently, suggesting that there might be a threshold level of DNA damage above which SAHF formation is triggered. This could be also related to the level of NOX4 expression and consequently to its activity. Previous studies have focused on transcriptional control of NOX4 as the principal mechanism of regulation (Serrander et al., 2007). Importantly, we observed a regulation of NOX4 transcription by H-RasV12. We cannot however exclude other mechanisms of regulation.

Activation and/or increased expression of other components of the H-Ras pathway, such as Racl, induced cellular senescence (Debidda et al., 2006). Several studies have implicated Rac-mediated production of ROS in a variety of cellular response and, in some endogenously NOX4-expressing cells, a Rac requirement for the NOX4-mediated ROS production has been shown (Gorin et al., 2003). Moreover, increased expression of E2F transcription factors led also to premature senescence (Johnson and Degregori, 2006) and E2F factor(s) were recently shown to be positive regulators of NOX4 transcription in vascular smooth muscle cells (Zhang et al., 2008). Taken together these data suggest that NOX4 induced from distinct oncogenes could be a common genotoxic agent implied in senescence.

Oncogenic Ras is believed to have roles in the initiation and progression of thyroid tumors, based on the high frequency of Ras mutations found in benign and malignant thyroid tumors (Suarez et al., 1990; Tallini, 2002). However, it has also been shown that a telomere-independent mechanism in limiting H-RasV12 oncogene-driven proliferation of human thyroid epithelial cells can take place (Jones et al., 2000). Senescence is accompanied by upregulation of cyclin-dependent kinase inhibitors p21 and p16. In this study, H-RasV12 induced p21 expression and, treatment with NAC or siRNA-mediated abrogation of NOX4 expression inhibited $\mathrm{p} 21$ induction indicating that ROS produced via NOX4 regulated p21 expression. By contrast, there was no sign of p16 induction. Therefore, in agreement with previously published data obtained with human ovarian surface epithelial cells, inducible expression 
of $\mathrm{H}$-Ras in these human thyroid cells led to senescence by a mechanism that did not involve p16 (Nicke et al., 2005).

Our work demonstrates for the first time a crucial role for NOX4 in DNA damage induced by oncogenic $\mathrm{H}-$ Ras and consequently in the senescence process. Several reports have demonstrated that senescence is not merely an artifact of cell culture but occurs in vivo to limit tumor growth in mice and humans. DNA damage foci have been identified in early tumor precursor lesions and are proposed to occur as a consequence of activated oncogenes (Bartkova et al., 2005). It has been suggested that ROS could induce and maintain senescenceinduced tumor suppression (Takahashi et al., 2006). Thus, if function for ROS is to enforce irreversible cellular senescence, the NADPH oxidase NOX4, as ROS-generating system, appears to be a potential contributor to tumor suppression.

\section{Materials and methods}

\section{Plasmids, cells and stable transfection}

The human thyroid epithelial cell line (HThy-ori) was obtained from American Type Culture Collection and cultured in RPMI 1640 medium supplemented with $1 \%$ antibiotics-antimicotics (Invitrogen, Carlsbad, CA, USA), $2 \mathrm{~mm}$ of L-glutamine (Invitrogen), $10 \%$ fetal calf serum (PAA Laboratories, Pasching, Austria) and maintained at $37^{\circ} \mathrm{C}$ in a $5 \% \mathrm{CO}_{2}$ $95 \% \mathrm{O}_{2}$ mixture. $\mathrm{H}-\mathrm{R}$ as cDNA was isolated by a RT-PCR procedure using AmpliTaq Gold's protocol (Applied Biosystems, Foster City, CA, USA) and using total RNA isolated from human thyrocytes as a template. Primers were $5^{\prime}$ ATGACGGAATATAAGCTGGTGGT- $3^{\prime}$ and $5^{\prime}$-TCAGGA GAGCACACACTTGCAGCT-3' with EcoR1 sites added. The cDNA was cloned into the EcoRI sites of the tetracycline-inducible vector pcDNA4/TO (Invitrogen) and sequenced. The H-Ras mutant (H-RasV12) was generated by replacing glycine 12 by valine using the QuickChange SiteDirected Mutagenesis kit (Stratagene, La Jolla, CA, USA) and sequenced. To obtain tetracycline-inducible cell lines, pcDNA4TO-HRasV12 and pcDNA6/TR expressing the tetracycline (Tet) repressor (Invitrogen) were transfected into HThy-ori cells using FuGENE 6 (Roche Applied Science,
Indianapolis, IN, USA) and the cells were selected for resistance to zeocine $(100 \mu \mathrm{g} / \mathrm{ml})$ and blasticidine $(10 \mu \mathrm{g} / \mathrm{ml})$ for 20-30 days. Tet-on-regulated H-RasV12 HThy-ori cells were cultured in RPMI 1640 medium supplemented with Tetfree fetal calf serum (PAA laboratories).

\section{Real-time-PCR}

Total RNA from cells was extracted using Trizol reagent (Invitrogen, Inc.) according to the manufacturer's instructions. Quality of RNA preparation, based on the $28 \mathrm{~S} / 18 \mathrm{~S}$ ribosomal RNAs ratio, was assessed using the RNA 6000 Nano Lab-Onchip (Agilent Technologies, Palo Alto, CA, USA). Reverse transcription and real-time-PCR were performed as described previously (Weyemi et al., 2010). Oligonucleotides were purchased from MWG Biotech (Courtaboeuf, Les Ulis, France) and their sequences are available on demand.

\section{Transient transfection}

Tet-on-regulated H-RasV12 HThy-ori cells were transfected at $60 \%$ confluence with small interference RNA against NOX4 and $\mathrm{p} 22^{\text {phox }}$ listed in Table 1 or scrambled siRNA control ( Dharmacon, Lafeyette, CO, USA) by using the Jet Pei transfection reagent (Polyplus-Ozyme, Saint Quentin en Yvelines Cedex, France). Cells were incubated for $8 \mathrm{~h}$ with siRNA-Jet Pei complex in RPMI 1640 medium supplemented with $0.2 \%$ Tetracycline-free fetal calf serum; $1 \mu \mathrm{g} / \mathrm{ml}$ doxycycline was then added to medium for $48 \mathrm{~h}$. The knockdown efficiency was checked by qPCR and immunoblot assays. The pcDNA4TO-H-RasV12 vector and the pHyPer-nuc vector (Evrogen JSC, Moscow, Russia) were transiently transfected, respectively, into Tet-on-regulated H-RasV12 HThy-ori cells using the Jet Pei transfection reagent (Polyplus) according to the manufacturer's protocol.

\section{Immunofluorescence}

Cells were plated at $2 \times 10^{5} /$ well in 6-well plates in RPMI 1640 medium as described in cell cultures. Cells were fixed for $30 \mathrm{~min}$ with freshly prepared $4 \%$ paraformaldehyde in phosphate-buffered saline (PBS). After washing with PBS, the cells were permeabilized for $10 \mathrm{~min}$ in PBS plus sodium dodecyl sulfate $0.1 \%$. The cells were then blocked with $10 \%$ fetal calf serum for $30 \mathrm{~min}$ and incubated for $1 \mathrm{~h}$ at room temperature with primary antibody diluted in PBS plus $0.1 \%$ bovine serum albumin: p22 $2^{\text {phox }}$ (sc-20781 Santa Cruz Biotechnology, Santa Cruz, CA, USA); NOX4 (CO 80160, Novus

Table 1 Sequences of selected siRNA against NOX4 and $\mathrm{p} 22^{\text {phox }}$

\begin{tabular}{|c|c|c|}
\hline Product (manufacturer) & Name of siRNA & Sequence \\
\hline siNOX4 & NOX4-1 & $5^{\prime}$-ACUAUGAUAUCUUCUGGUA-3' \\
\hline \multirow{3}{*}{ SMARTpool (Dharmacon) } & NOX4-2 & 5'-GAAAUUAUCCCAAGCUGUA-3' \\
\hline & NOX4-3 & $5^{\prime}$-GGGCUAGGAUUGUGUCUAA- $3^{\prime}$ \\
\hline & NOX4-4 & $5^{\prime}$-GAUCACAGCCUCUACAUAU-3' \\
\hline \multirow[t]{4}{*}{ sip22 $2^{\text {phox }}$ pool (Dharmacon) } & p22 $2^{\text {phox }}-1$ & $5^{\prime}$-CCAUGUGGGCCAACGAACA-3' \\
\hline & p22 $2^{\text {phox }}-2$ & $5^{\prime}$-GAAGAAGGGCUCCACCAUG-3' \\
\hline & p22 $2^{\text {phox }}-3$ & $5^{\prime}$-GUACAUGACCGCCGUGGUG-3' \\
\hline & p22 $2^{\text {phox }}-4$ & 5'-UACCAGGAAUUACUAUGUU-3' \\
\hline \multirow[t]{6}{*}{ Stealth RNAi duplex (Invitrogen) } & NOX4-1 & 5'-GGAGAACCAGGAGAUUGUUGGAUAA-3' \\
\hline & & 5'-UUAUCCAACAAUCUCCUGGUUCUCC-3' \\
\hline & NOX4-2 & 5'-AGAGUGAAGACUUUGUUGAACUGAA-3' \\
\hline & & 5'-UUCAGUUCAACAAAGUCUUCACUGU-3' \\
\hline & NOX4-3 & 5'-CCUCAUGAUCACAGCCUCUACAUAU-3' \\
\hline & & $5^{\prime}$-AUAUGUAGAGGCUGUGAUCAUGAGG-3' \\
\hline
\end{tabular}


Biologicals, Littleton, CO, USA), $\gamma$-H2A.X (05-636, Millipore, Billerica, MA, USA); calreticulin (ab2907, Abcam, Cambridge, MA, USA); green fluorescent protein (11814460001 Roche); HP-1 $\beta$ (MAB3448, Millipore); PML (sc-5621 Santa cruz). After washing in PBS plus $0.1 \%$ bovine serum albumin, the cells were stained with an Alexa fluor 488 or Alexa fluor 568 antibody (Invitrogen) for $1 \mathrm{~h}$ at room temperature. Finally, the cells were washed in PBS and coverslips were mounted for analysis. Fluorescent images were captured using a confocal microscope (Leica DM IRE 2, Perkin Elmer, Waltham, MA, USA).

\section{Intracellular ROS detection}

Intracellular ROS levels were measured by flow cytometry in cells loaded with the redox-sensitive dye DCFH-DA (Invitrogen, Molecular probe) as described previously (Weyemi et al., 2010).

pHyPer-transfected cells were plated to glass-bottom dishes, treated with doxycycline $(1 \mu \mathrm{g} / \mathrm{ml})$ and analyzed by confocal microscopy. The fluorescence (excitation/emission: 488/ $530 \mathrm{~nm}$ ) was examined under an LSM 510 confocal microscope (Zeiss, Jena, Germany).

\section{Pulsed-field gel electrophoresis}

Cells were washed once with ice-cold PBS, trypsinized and included into agarose plugs. Plugs were prepared by adding equal volume of cell samples (at the concentration of $2 \times 10^{6}$ cells $/ \mathrm{ml})$ to low-melting-point agarose $(0.5 \mathrm{ml}, 1.6 \%)$ and let set for $1 \mathrm{~h}$ at $4{ }^{\circ} \mathrm{C}$. Plugs were then placed in $1.5 \mathrm{ml}$ of lysis solution $(0.5 \mathrm{~m}$ EDTA at $\mathrm{pH} 7.6,2 \%$ sarkosyl, $1 \%$ proteinase $\mathrm{K}$ and $2 \mathrm{~mm}$ deferoxamine) and incubated at $50^{\circ} \mathrm{C}$ for $38 \mathrm{~h}$ (Boucher et al., 2006). After two washes with TE (10 mm Tris$\mathrm{HCl}, 1 \mathrm{~mm}$ EDTA, pH 7.6) containing $0.1 \mathrm{~mm}$ deferoxamine and a 1-h incubation at room temperature with TE- $0.1 \mathrm{~mm}$ PMSF, plugs were stored at $4{ }^{\circ} \mathrm{C}$ in $0.05 \mathrm{M}$ EDTA and $0.1 \mathrm{~mm}$ deferoxamine. Pulse-field gel electrophoresis was performed with a neutral $0.7 \%$ agarose gel in Tris-acetic acid-EDTA buffer using clamped homogenous electric fields-Mapper (Bio-Rad, Marnes-la-Coquette, France), for 74-h running time at $2 \mathrm{~V} / \mathrm{cm}$ with a reorientation angle $\left(106^{\circ}\right)$ and a $35-\mathrm{min}$ pulse switch time.

\section{Nuclei extraction}

Nuclei were extracted using Nuclei EZ prep nuclei isolation kit (Sigma-Aldrich, St Louis, MO, USA) according to the manufacturer's instructions. Briefly, cells were harvested and lysed on ice with Nuclei EZ lysis buffer. Nuclei were collected by centrifugation at $500 \mathrm{~g}$ for $5 \mathrm{~min}$ at $4{ }^{\circ} \mathrm{C}$. The clear supernatant was submitted to centrifugation at $200000 \mathrm{~g}$. The detergent-insoluble pellet and the nuclei pellet were resuspended in modified RIPA buffer $(0.025 \mathrm{M}$ Tris $/ \mathrm{HCl} \mathrm{pH} \mathrm{7.4,}$ $0.15 \mathrm{M} \mathrm{NaCl}, 0.5 \%$ Triton $\mathrm{X}-100,0.1 \%$ sodium dodecyl sulfate, $0.1 \%$ sodium deoxycholate and protease inhibitor cocktail (Sigma)) for western blot analysis. Quality and integrity of nuclei fraction were analyzed by microscopy after 4',6-diamidino-2-phenylindole staining.

Cell survival test

Cell proliferation/viability of H-RasV12-inducible HThy-ori cells (24-well plates; $10^{4}$ cells/well) was assayed using the WST-1 assay according to the manufacturer's instructions. Cells were transduced with siRNA control or siRNA against NOX4 $24 \mathrm{~h}$ before treatment with doxycycline $(1 \mu \mathrm{g} / \mathrm{ml})$ for indicated times.

\section{Annexin $V$ staining}

Cells were suspended in binding buffer (BD Pharmingen, San Diego, CA, USA) and stained with FITC Annexin V (1/20) in binding buffer for $15 \mathrm{~min}$ at room temperature in the dark. Cells were resuspended in $400 \mu \mathrm{l}$ binding buffer and immediately analyzed by FACSCalibur (BD Biosciences, San Diego, CA, USA).

\section{Western blots}

Cells were washed twice with PBS, directly solubilized in denaturing sample buffer and then subjected to sodium dodecyl sulfate-polyacrylamide gel electrophoresis as described previously (Moskaluk et al., 2002). Proteins were electrotransferred to $0.2 \mu \mathrm{m}$ Protan BA 83 (Schleicher and Schuell, Mantes la ville, France) for immunodetection. Primary antibodies: NOX4 (CO 80160, Novus biologicals); p22 ${ }^{\text {phox }}$ (sc-20781 Santa Cruz Biotechnology); $\gamma$-H2A.X (05636, Millipore); p21 (sc-397 Santa Cruz Biotechnology); HRas (sc-520 Santa Cruz Biotechnology); green fluorescent protein (11814460001 Roche); CDC6 (3387S Cell Signaling, Danvers, MA, USA). Immune complexes were detected with horseradish peroxidase coupled anti-rabbit IgG antibody (Southern Biotech, Birmingham, AL, USA).

\section{Immunohistochemistry}

H-RasV12-inducible HThy-ori cells and NOX4-inducible HEK293 cells (kindly given by Karl-Heinz Krause (University of Geneva, Switzerland)) were pelleted by centrifugation and the media carefully aspirated. Formaldehyde was carrefully added to the tube. The cell pellet was allowed to fix overnight at $4{ }^{\circ} \mathrm{C}$. The formaldehyde was removed, and the cell pellet was carefully dislodged. Before processing, $30 \mathrm{ml}$ of standard $2 \%$ agarose was poured into a $100 \mathrm{~mm}$ bacterial petri dish and allowed to set. Doughnut-shaped agarose molds were made by making concentric circles in the agarose. The fixed cell pellets were packed into the center of the molds with a small spatula. The processed plugs were then embedded in paraffin. Immunohistochemical study was performed on formaldehyde-fixed, paraffin-embedded cells as described previously (Weyemi et al, 2010). Sections were incubated for $60 \mathrm{~min}$ at room temperature with the rabbit polyclonal anti-NOX4 antiserum $(1: 100)$, they were then washed in Tris- $\mathrm{HCl} 1 \times$ buffer for $5 \mathrm{~min}$ and incubated with a peroxidase-conjugated goat anti-rabbit antibody for $30 \mathrm{~min}$ (ENVISION; DAKO Corp., Carpinteria, CA, USA). After further washes, peroxidase staining was revealed in diaminobenzidine tetrahydrochloride (Polysciences Inc., Warrington, PA, USA) with $0.1 \%$ (w/v) of hydrogen peroxide, in Tris buffer, $0.01 \mathrm{~mol} / 1(\mathrm{pH} 7.2)$. Sections were counterstained and mounted. Negative controls were obtained by replacing the specific primary antibody by an irrelevant antibody.

\section{Statistical analysis}

The tests were performed using the GraphPadInstat software (GraphPad, La Jolla, CA, USA) for analysis of variance, and Student's $t$-test with the level of significance set at $P<0.05$.

\section{Conflict of interest}

The authors declare no conflict of interest. 


\section{Acknowledgements}

Urbain Weyemi is the recipient of a grant from the Fondation pour la Recherche Médicale (FRM). We are indebted to Didier Méthivier from Unité U848 INSERM, Villejuif,
F-94805, France for his assistance in flow cytometry. This work was supported by grants from Electricité de France (EDF), Association pour la Recherche sur le Cancer (ARC), Ligue Contre le Cancer (comité du Val-de Marne) and Agence Nationale de la Recherche (ANR).

\section{References}

Abulaiti A, Fikaris AJ, Tsygankova OM, Meinkoth JL. (2006). Ras induces chromosome instability and abrogation of the DNA damage response. Cancer Res 66: 10505-10512.

Anilkumar N, Weber R, Zhang M, Brewer A, Shah AM. (2008). Nox4 and nox2 NADPH oxidases mediate distinct cellular redox signaling responses to agonist stimulation. Arterioscler Thromb Vasc Biol 28: 1347-1354.

Bartkova J, Horejsi Z, Koed K, Kramer A, Tort F, Zieger K et al. (2005). DNA damage response as a candidate anti-cancer barrier in early human tumorigenesis. Nature 434: 864-870.

Bartkova J, Rezaei N, Liontos M, Karakaidos P, Kletsas D, Issaeva N et al. (2006). Oncogene-induced senescence is part of the tumorigenesis barrier imposed by DNA damage checkpoints. Nature 444: 633-637.

Bedard K, Krause KH. (2007). The NOX family of ROS-generating NADPH oxidases: physiology and pathophysiology. Physiol Rev 87: 245-313.

Belousov VV, Fradkov AF, Lukyanov KA, Staroverov DB, Shakhbazov KS, Terskikh AV et al. (2006). Genetically encoded fluorescent indicator for intracellular hydrogen peroxide. Nat Methods 3: 281-286.

Boucher D, Testard I, Averbeck D. (2006). Low levels of clustered oxidative DNA damage induced at low and high LET irradiation in mammalian cells. Radiat Environ Biophys 45: 267-276.

Chiera F, Meccia E, Degan P, Aquilina G, Pietraforte D, Minetti M et al. (2008). Overexpression of human NOX1 complex induces genome instability in mammalian cells. Free Radic Biol Med 44: 332-342.

Collado M, Serrano M. (2006). The power and the promise of oncogene-induced senescence markers. Nat Rev Cancer 6: 472-476.

d'Adda di Fagagna F, Reaper PM, Clay-Farrace L, Fiegler H, Carr P, Von Zglinicki T et al. (2003). A DNA damage checkpoint response in telomere-initiated senescence. Nature 426: 194-198.

Debidda M, Williams DA, Zheng Y. (2006). Rac1 GTPase regulates cell genomic stability and senescence. $J$ Biol Chem 281: 38519-38528.

Di Micco R, Fumagalli M, Cicalese A, Piccinin S, Gasparini P, Luise $\mathrm{C}$ et al. (2006). Oncogene-induced senescence is a DNA damage response triggered by DNA hyper-replication. Nature 444: 638-642.

Geiszt M, Kopp JB, Varnai P, Leto TL. (2000). Identification of renox, an NAD(P)H oxidase in kidney. Proc Natl Acad Sci USA 97: 8010-8014.

Gorgoulis VG, Vassiliou LV, Karakaidos P, Zacharatos P, Kotsinas A, Liloglou $\mathrm{T}$ et al. (2005). Activation of the DNA damage checkpoint and genomic instability in human precancerous lesions. Nature 434: 907-913.

Gorin Y, Ricono JM, Kim NH, Bhandari B, Choudhury GG, Abboud HE. (2003). Nox4 mediates angiotensin II-induced activation of Akt/protein kinase B in mesangial cells. Am J Physiol Renal Physiol 285: F219-F229.

Gruhne B, Sompallae R, Marescotti D, Kamranvar SA, Gastaldello S, Masucci MG. (2009). The Epstein-Barr virus nuclear antigen-1 promotes genomic instability via induction of reactive oxygen species. Proc Natl Acad Sci USA 106: 2313-2318.

Guerra C, Schuhmacher AJ, Canamero M, Grippo PJ, Verdaguer L, Perez-Gallego L et al. (2007). Chronic pancreatitis is essential for induction of pancreatic ductal adenocarcinoma by K-Ras oncogenes in adult mice. Cancer Cell 11: 291-302.
Hemann MT, Narita M. (2007). Oncogenes and senescence: breaking down in the fast lane. Genes Dev 21: 1-5.

Hilenski LL, Clempus RE, Quinn MT, Lambeth JD, Griendling KK. (2004). Distinct subcellular localizations of Nox 1 and Nox4 in vascular smooth muscle cells. Arterioscler Thromb Vasc Biol 24: $677-683$.

Johnson DG, Degregori J. (2006). Putting the oncogenic and tumor suppressive activities of E2F into context. Curr Mol Med 6: 731-738.

Jones CJ, Kipling D, Morris M, Hepburn P, Skinner J, Bounacer A et al. (2000). Evidence for a telomere-independent "clock" limiting RAS oncogene-driven proliferation of human thyroid epithelial cells. Mol Cell Biol 20: 5690-5699.

Krause KH. (2004). Tissue distribution and putative physiological function of NOX family NADPH oxidases. Jpn J Infect Dis 57: S28-S29.

Kuroda J, Nakagawa K, Yamasaki T, Nakamura K, Takeya R, Kuribayashi F et al. (2005). The superoxide-producing NAD(P)H oxidase Nox4 in the nucleus of human vascular endothelial cells. Genes Cells 10: 1139-1151.

Lee AC, Fenster BE, Ito H, Takeda K, Bae NS, Hirai T et al. (1999). Ras proteins induce senescence by altering the intracellular levels of reactive oxygen species. $J$ Biol Chem 274: 7936-7940.

Leikam C, Hufnagel A, Schartl M, Meierjohann S. (2008). Oncogene activation in melanocytes links reactive oxygen to multinucleated phenotype and senescence. Oncogene 27: 7070-7082.

Lener B, Koziel R, Pircher H, Hutter E, Greussing R, HerndlerBrandstetter D et al. (2009). The NADPH oxidase Nox4 restricts the replicative lifespan of human endothelial cells. Biochem $J \mathbf{4 2 3}$ : 363-374.

Lin AW, Barradas M, Stone JC, van Aelst L, Serrano M, Lowe SW. (1998). Premature senescence involving p53 and p16 is activated in response to constitutive MEK/MAPK mitogenic signaling. Genes Dev 12: 3008-3019.

Lin AW, Lowe SW. (2001). Oncogenic ras activates the ARF-p53 pathway to suppress epithelial cell transformation. Proc Natl Acad Sci USA 98: 5025-5030.

Liu L, Rodriguez-Belmonte EM, Mazloum N, Xie B, Lee MY. (2003). Identification of a novel protein, PDIP38, that interacts with the p50 subunit of DNA polymerase delta and proliferating cell nuclear antigen. J Biol Chem 278: 10041-10047.

Lyle AN, Deshpande NN, Taniyama Y, Seidel-Rogol B, Pounkova L, Du P et al. (2009). Poldip2, a novel regulator of Nox4 and cytoskeletal integrity in vascular smooth muscle cells. Circ Res 105: 249-259.

MacLaren A, Black EJ, Clark W, Gillespie DA. (2004). c-Jun-deficient cells undergo premature senescence as a result of spontaneous DNA damage accumulation. Mol Cell Biol 24: 9006-9018.

Mallette FA, Gaumont-Leclerc MF, Ferbeyre G. (2007). The DNA damage signaling pathway is a critical mediator of oncogeneinduced senescence. Genes Dev 21: 43-48.

Nicke B, Bastien J, Khanna SJ, Warne PH, Cowling V, Cook SJ et al. (2005). Involvement of MINK, a Ste20 family kinase, in Ras oncogene-induced growth arrest in human ovarian surface epithelial cells. Mol Cell 20: 673-685.

Nuciforo PG, Luise C, Capra M, Pelosi G, d'Adda di Fagagna F. (2007). Complex engagement of DNA damage response pathways in human cancer and in lung tumor progression. Carcinogenesis 28: 2082-2088. 
Petersen BO, Wagener C, Marinoni F, Kramer ER, Melixetian M, Lazzerini Denchi E et al. (2000). Cell cycle- and cell growthregulated proteolysis of mammalian CDC6 is dependent on APCCDH1. Genes Dev 14: 2330-2343.

Quintanilla M, Brown K, Ramsden M, Balmain A. (1986). Carcinogen-specific mutation and amplification of Ha-ras during mouse skin carcinogenesis. Nature 322: 78-80.

Sarkisian CJ, Keister BA, Stairs DB, Boxer RB, Moody SE, Chodosh LA. (2007). Dose-dependent oncogene-induced senescence in vivo and its evasion during mammary tumorigenesis. Nat Cell Biol 9 : 493-505.

Schilder YD, Heiss EH, Schachner D, Ziegler J, Reznicek G, Sorescu $\mathrm{D}$ et al. (2009). NADPH oxidases 1 and 4 mediate cellular senescence induced by resveratrol in human endothelial cells. Free Radic Biol Med 46: 1598-1606.

Serrander L, Cartier L, Bedard K, Banfi B, Lardy B, Plastre O et al. (2007). NOX4 activity is determined by mRNA levels and reveals a unique pattern of ROS generation. Biochem J 406: 105-114.

Serrano M, Lin AW, McCurrach ME, Beach D, Lowe SW. (1997) Oncogenic ras provokes premature cell senescence associated with accumulation of p53 and p16INK4a. Cell 88: 593-602.

Suarez HG, du Villard JA, Severino M, Caillou B, Schlumberger M, Tubiana $\mathrm{M}$ et al. (1990). Presence of mutations in all three ras genes in human thyroid tumors. Oncogene 5: 565-570.

Takahashi A, Ohtani N, Yamakoshi K, Iida S, Tahara H, Nakayama $\mathrm{K}$ et al. (2006). Mitogenic signalling and the p16INK4a-Rb pathway cooperate to enforce irreversible cellular senescence. Nat Cell Biol 8: 1291-1297.

Tallini G. (2002). Molecular pathobiology of thyroid neoplasms. Endocr Pathol 13: 271-288.

Vafa O, Wade M, Kern S, Beeche M, Pandita TK, Hampton GM et al. (2002). c-Myc can induce DNA damage, increase reactive oxygen species, and mitigate p53 function: a mechanism for oncogeneinduced genetic instability. Mol Cell 9: 1031-1044.

Weyemi U, Caillou B, Talbot M, Ameziane-El-Hassani R, Lacroix L, Lagent-Chevallier $\mathrm{O}$ et al. (2010). Intracellular expression of reactive oxygen species-generating NADPH oxidase NOX4 in normal and cancer thyroid tissues. Endocr Relat Cancer 17: $27-37$.

Zhang L, Sheppard OR, Shah AM, Brewer AC. (2008). Positive regulation of the NADPH oxidase NOX4 promoter in vascular smooth muscle cells by E2F. Free Radic Biol Med 45: 679-685.

Zhang R, Poustovoitov MV, Ye X, Santos HA, Chen W, Daganzo SM et al. (2005). Formation of MacroH2A-containing senescenceassociated heterochromatin foci and senescence driven by ASF1a and HIRA. Dev Cell 8: 19-30.

(c) This work is licensed under the Creative Commons Attribution-NonCommercial-No Derivative Works 3.0 Unported License. To view a copy of this license, visit http://creativecommons.org/licenses/by-nc-nd/3.0/

Supplementary Information accompanies the paper on the Oncogene website (http://www.nature.com/onc) 